\title{
Indigenous Method and Safety of Mitomycin C in Refractory Corrosive Esophageal Strictures
}

\author{
Neeraj Nagaich ${ }^{1 *}$, Radha Sharma ${ }^{2}$, Ashish kumar Jha², Subhash Nepalia ${ }^{3}$ and Sandeep Nijhawan ${ }^{3}$ \\ ${ }^{1}$ Department of Gastroenterology, Fortis Escorts Hospital, India \\ ${ }^{2}$ Department of Gastroenterology, MG Medical College, India \\ ${ }^{3}$ Department of Gastroenterology, SMS Hospital, India
}

Submission: February 10, 2017; Published: April 19, 2017

"Corresponding author: Neeraj Nagaich, Consultant Gastroenterology, Fortis Escorts Hospital, JLN Marg, Malviyanagar, Jaipur, 302017, India, Tel: 9414600141; Email: drneerajn@gmail.com

\begin{abstract}
Increasingly frequent dilation may become a self-defeating cycle in refractory stricture as recurrent trauma enhance, scar formation, and ultimately recurrence and potential worsening of the stricture. In twelve patients of caustic induced esophageal stricture, who failed to respond despite rigorous dilatation regimen for more than one year, a trial of topical mitomycin -C application to improve dilatation results was undertaken, considering the recently reported efficacy and safety of this agent. No data available on safety and efficacy of Mitomycin c in refractory strictures. Mitomycin c was applied for 2 to 3 minutes at the strictured oesophageal segment after dilation with wire guided SG dilator. Patient was kept NBM for 2-3 hour. After 4-6 sessions of Mitomycin-C treatment resolution of symptoms and significant improvement in dysphagia score and PDI was seen in all 12 patients. Mitomycin-C, topical application may be a useful strategy in refractory corrosive oesophageal strictures and salvage patients from surgery. This study suggests safety and efficacy of Mitomycin c in refractory strictures.
\end{abstract}

Keywords: Refractory Stricture; Mitomycin-c; periodic dilatation index (PDI)

\section{Introduction}

Caustic esophageal strictures still represent a challenge to endoscopist. Standard treatment is regular esophageal dilatation until the resolution of dysphagia. Caustic strictures require dilations more frequently for a positive clinical response [1]. Increasingly frequent dilation may become a selfdefeating cycle in refractory stricture as recurrent trauma to the mucosa, enhance scar formation through enhanced fibroblast proliferation and collagen deposition, and ultimately recurrence and potential worsening of the stricture [2,3]. In many cases endoscopic dilatation fails and therefore esophageal replacement is eventually required. Non operative management of refractory stricture is limited. No data available on safety and efficacy of Mitomycin c in refractory strictures.

\section{Materials and Methods}

This hospital based observational descriptive study was done during april 2011- dec 2012 in Department of gastroenterology, SMS medical college, Jaipur to assess the efficacy of topical mitomycin-C in refractory caustic induced esophageal stricture. Twelve patients of refractory caustic esophageal strictures who reported in our department were enrolled as and when they met the inclusion criteria, last case was enrolled six months before Dec-2012. After obtaining informed consent, a trial of topical mitomycin-C application to improve dilatation results was undertaken, considering the recently reported efficacy and safety of this agent, in refractory stricture [4,5]. Baseline characteristic of all patients i.e age, sex, number of strictures duration of treatment dysphagia score ,periodic dilation index(PDI) etc were recorded from available records.

A cotton pledget held by endoscopic forceps was soaked in a $0.4-\mathrm{mg} / \mathrm{mL}$ solution of mitomycin-C and was then applied topically under direct vision, by front-loading the pledget in a standard cap used for band ligation of varices attached to the end of the endoscope, to prevent the mitomycin-C from touching normal mucosa. This was applied for 2 to 3 minutes at the strictured oesophageal segment after dilation with wire guided SG dilator. After the application patient was kept nill by mouth for 2-3 hour. All patients were observed for local and systemic side effect during 24 hours of admission after each local application of Mitomycin c and on discharge patients were instructed to report back if they have any complaint thereafter. No local or 
systemic side effects resulting from mitomycin-C application was observed. Topical application was repeated at 4 week interval along with scheduled dilatation sessions every week. The ability to swallow was expressed as a dysphagia score. The scoring system was modified from that reported by Mellow and Pinkas; a score of 0 denoted the ability to eat a normal diet; 1 , the ability to eat some solid food; 2 , the ability to eat semisolid only; 3 , the ability to swallow liquids only; and 4, complete dysphagia [6].

A periodic dilation index (number of dilations required per month) before and after MC application was calculated. All these parameters were re-recorded at four or six months after topical application of mitomycin-C. The periodic dilatation index (PDI) was calculated for the last 12 week duration in all patients.

The end point of successful outcome of the treatment was considered when once 14 size dilator could be passed easily and dysphagia score improved by one grade from baseline. End point data was collected in 6 patient at 4 month, 5 patients at 5 months and in 2 patients at 6 months.

\section{Results}

The average no. of (times) dilatation, the study subjects underwent before MC application was 58.6 (SD 8.4) with a mean duration of dilatation 14.7 (SD is 2.3). The average no of application of topical mitomycin c among cases was 4.75 (SD 0.75). The average Dysphagia score before application of topical mitomycin was 2.5 (SD 0.52), which reduced to 0.91 (SD 0.66) after application. This depicts a statistically significant reduction in dysphagia score after MC. $(\mathrm{P}<0.0001 /$ paired $t$ test $)$.

The average PDI before MC was 3.99 (SD 0.36) that was reduced to 2.58 (SD 0.32) after MC. Interpretation-There was a statistically significant reduction in average PDI score after MC ( $\mathrm{P}<0.0001 /$ paired $\mathrm{t}$ test). After 4-6 sessions of Mitomycin-C treatment, significant clinical improvement on follow-up endoscopy ( $>14$ fr. Dilator passed easily), and resolution of symptoms and marked improvement in dysphagia score was seen in all 12 patients. The PDI calculated for 12 weeks following $\mathrm{MC}$ application also decreased significantly in all the patients.

\section{Discussion}

Mitomycin c, an anthracycline derived alkylating agent from streptomyces caespitous, has antineoplastic and anti proliferative properties. It inhibits DNA and protein synthesis, has been shown to inhibit fibroblast proliferation and collagen synthesis and may prevent stricture recurrence by interfering with normal wound healing processes [2,4]. It's anti proliferative properties on fibroblasts have been shown in vivo and in vitro [7].

Favorable clinical responses to the topical application of Mitomycin-C reducing scar formation have recently been reported in the treatment of surgical wound healing and adhesions [8]. Mitomycin C should be applied precisely only to the stricture mucosa. Various techniques have been used to topically deliver Mitomycin-C to the anastomotic stricture [5]. Mucosal application of Mitomycin-C has been shown to be an effective and safe treatment of recalcitrant esophageal stricture [5]. Concentrations of the Mitomycin-C described in the various anatomical regions vary however the concentration of $0.4 \mathrm{mg} / \mathrm{mL}$ is most commonly used one. This anti fibroblastic approach may be used in preference to steroid application locally or systemically, in which the results have not been rewarding because these agents approach the problem from an anti-inflammatory angle rather than the more appropriate anti scarring post dilation mode.

Majority of prior studies [4,5] of mitomycin c application were in pediatric age patient, in this study all the patients were above 16 year age thus suggesting efficacy of topical Mitomycin c in adult patients also. The use of Mitomycin-C seems to improve the outcome by making stricture supple early and large size dilators can be passed easily and early. The optimal duration of Mitomycin c application has yet to be determined. Further studies may validate this weapon for recalcitrant strictures.

\section{Conclusion}

Post dilatation application of topical Mitomycin-C resulted in major success in endoscopic and symptomatic criteria, and it may be a useful strategy in corrosive esophageal strictures refractory to repeated endoscopic dilatation. This study suggests safety and efficacy of Mitomycin c in refractory strictures.

\section{References}

1. Broor SL, Lahoti D, Bhose PP (1996) Benign esophageal strictures in children and adolescents: etiology, clinical profile, and results of endoscopic dilation. Gastrointest Endosc 43: 474-477.

2. Cheng Y, Li M, Yang R (2003) Restenosis following balloon dilation of benign oesophageal stenosis. World J Gastroerol 9(11): 2605-2608.

3. Lisy J, Hetkova M, Snajdauf J (1998) Long-term outcomes of balloon dilations of oesophageal strictures in children. Acad Radiol 5: 832-835.

4. S Rosseneu, N Afzal, B Yerushalmi (2007) Topical Application of Mitomycin-C in Oesophageal Strictures. Journal of Pediatric Gastroenterology and Nutrition 44: 336-341.

5. Mellow MH, Pinkas H (1985) Endoscopic laser therapy for malignancies affecting the esophagus and gastroesophageal junction. Analysis of technical and functional efficacy. Arch Intern Med 145(8): 1443-1446.

6. Sewall GK, Robertson KM, Connor NP (2003) Effect of topical mitomycin on skin wound contraction. Arch Facial Plast Surg 5(1): 59-62.

7. Khaw PT, Doyle JW, Sherwood MB (1993) Prolonged localized tissue effects from 5-minute exposure to fluorouracil and mitomycin. Arch Ophthalmol 111(2): 263-267.

8. Spier BJ, Sawma VA, Gopal DV (2009) Intralesional mitomycin C: successful treatment for benign recalcitrant esophageal stricture. Gastrointest Endosc 69(1): 152-153. 
(C) This work is licensed under Creative

DOI: $10.19080 /$ ARGH.2017.04.555644
Your next submission with JuniperPublishers will reach you the below assets

- Quality Editorial service

- Swift Peer Review

- Reprints availability

- E-prints Service

- Manuscript Podcast for convenient understanding

- Global attainment for your research

- Manuscript accessibility in different formats

( Pdf, E-pub, Full Text, audio)

- Unceasing customer service

Track the below URL for one-step submission https://juniperpublishers.com/online-submission.php 